\title{
Perbandingan Penggunaan Pasir Lumajang dengan Pasir Gunung Merapi terhadap Kuat Tekan Beton
}

\author{
Dewi Pertiwi $^{1)}$, Boedi Wibowo ${ }^{2)}$, Endang Kasiati ${ }^{2)}$, Triaswati ${ }^{2)}$, Ari Gandhi \\ Sabban ${ }^{2)}$ \\ ${ }^{1)}$ Jurusan Teknik Sipil ITATS, ${ }^{2)}$ Program Diploma Teknik Sipil FTSP ITS \\ Email :en_kas@ce.its.ac.id
}

\begin{abstract}
Concrete Is a function of constituting materials consisting of hydraulic cement materials, coarse aggregate, fine aggregate, water, and additional materials. In research, there are two kinds of fine aggregate used i.e. Lumajang Sand and Mount Merapi Sand. Such research is trying to do Comparison Of Lumajang Sand With Mount Merapi Sand Against Compressive Strength Of Concrete. Method of manufacture of concrete using cylindrical test objects $(\emptyset 15 \mathrm{~cm}$, height $30 \mathrm{~cm})$ with a compressive strength plans $30 \mathrm{Mpa}$, using variations of Cement Water Factor (CWF) 0.4, 0.5, 0.4 and 0.3 and added with Fly Ash 20\%. Of research results obtained on tap CWF 0,6 Lumajang Sand and Mount Merapi Sand is not availabe because results of the strong concrete i.e 273,964 kg/cm and 270,090 $\mathrm{kg} / \mathrm{cm}^{2}$ is under strong concrete plans $300 \mathrm{~kg} / \mathrm{cm}^{2}$, results that meet the strong concrete plans on tap CWF 0.5 Lumajang sand experienced an increase of $27 \%$ i.e. $411,499 \mathrm{~kg} / \mathrm{cm}^{2}$, whereas Mount Merapi sand experienced an increase of $22.9 \%$ i.e. $389,351 \mathrm{~kg} / \mathrm{cm}^{2}$. On CWF 0.4 Lumajang sand experienced an increase of $32,6 \%$ i.e. $445,728 \mathrm{~kg} / \mathrm{cm}^{2}$, whereas Mount Merapi sand experienced an increase of $36.5 \%$ i.e. $472,716 \mathrm{~kg} / \mathrm{cm}^{2}$. On CWF 0.3 Lumajang sand experienced an increase of $48.3 \%$ i.e. $580,432 \mathrm{~kg} / \mathrm{cm}^{2}$, whereas Mount Merapi Sand experienced an increase of $54,7 \%$ i.e. $663,224 \mathrm{~kg} / \mathrm{cm}^{2}$.
\end{abstract}

Keyword: CWF, compressive strength of concrete, Lumajang sand, Mount Merapi sand

Abstrak

Beton merupakan fungsi dari bahan penyusunnya yang terdiri dari bahan semen hidrolik, agregat kasar, agregat halus, air, dan bahan tambahan. Dalam penelitian ini ada dua jenis agregat halus yang dipergunakan yakni pasir lumajang dan pasir gunung merapi. Pasir gunung Merapi merupakan pasir dengan kualitas baik, dikarenakan partikelnya yang memiliki sudut. Pola partikel yang memiliki sudut itulah yang membuat ikatan pasir gunung merapi degan semen menjadi lebih kuat. Berdasarkan hal tersebut penelitian ini mencoba untuk melakukan perbandingan pasir lumajang dengan pasir gunung merapi terhadap kuat tekan beton. Metode pembuatan benda uji menggunakan bet on silinder $(\varnothing 15 \mathrm{~cm}$, tinggi $30 \mathrm{~cm})$ dengan kuat tekan rencana $30 \mathrm{Mpa}$, menggunakan variasi Faktor Air Semen (FAS) 0.6, 0.5, 0,4 dan 0,3 serta dicampurkan dengan Fly Ash 20\%. Dari hasil penelitian didapatkan hasil pada FAS 0,6 kuat tekan beton untuk pasir Lumajang sebesar 273,964 dan pasir Gunung Merapi 270,094 ini semua tidak memenuhi kuat tekan rencana ,yang memenuhi kuat tekan beton rencana yakni pada FAS 0,5 pasir Lumajang mengalami peningkatan sebesar 27\% yakni $411,499 \mathrm{~kg} / \mathrm{cm}^{2}$, sedangkan pasir Gunung Merapi mengalami peningkatan sebesar $22,9 \%$ yakni $389,351 \mathrm{~kg} / \mathrm{cm}^{2}$. Pada FAS 0,4 pasir Lumajang mengalami peningkatan sebesar $32,6 \%$ yakni $445,728 \mathrm{~kg} / \mathrm{cm}^{2}$, sedangkan pasir Gunung Merapi mengalami peningkatan sebesar $36,5 \%$ yakni $472,716 \mathrm{~kg} / \mathrm{cm}^{2}$. Pada FAS 0,3 pasir Lumajang mengalami peningkatan sebesar $48,3 \%$ yakni $580,432 \mathrm{~kg} / \mathrm{cm}^{2}$, sedangkan Pasir Gunung Merapi mengalami peningkatan sebesar $54,7 \%$ yakni $663,224 \mathrm{~kg} / \mathrm{cm}^{2}$.

Kata Kunci : faktor air semen, kuat tekan beton, pasir Lumajang, pasir Gunung Merapi

J urnal APLIKASI: Media Informasi \& Komunikasi Aplikasi Teknik Sipil Terkini Halaman 13 


\section{Pendahuluan}

Beton merupakan salah satu unsur penting sebagai elemen pembentuk struktur yang banyak digunakan dewasa ini, hal ini dikarenakan beton mempunyai kelebihan antara lain :

1. Memiliki kekuatan yang tinggi.

2. Dapat di bentuk dengan bentuk dan ukuran yang di kehendaki.

3. Perawatan yang ekonomis.

4. Mudah di laksanakan dari pada bahan kontruksi yang lain.

5. Awet dan tahan terhadap cuaca serta api. (durability)

Bahan pokok penyusun beton antara lain semen, air, pasir (agregat halus) dan batu pecah (agregat kasar). Bahan air dan semen disatukan akan membentuk pasta semen, dan berfungsi sebagai bahan pengikat. Sedangkan pasir (agregat halus) dan batu pecah (agregat kasar) berfungsi sebagai bahan pengisi.

Saat ini telah dilakukan berbagai inovasi untuk mencari material alternatif untuk pembuatan beton. Salah satunya dengan mencari agregat halus yang efisien dan memiliki kuat tekan yang optimum. Dimana dalam penelitian ini menggunakan dua agregat halus yaitu pasir Lumajang dan pasir Gunung Merapi.

Oleh karena itu, dalam penelitian ini tentang 'Perbandingan Pasir Lumajang Dengan Pasir Gunung Merapi Terhadap Kuat Tekan Beton. Dimana dalam pemanfaatannya diharapkan dapat menemukan hasil kuat tekan beton yang baik.

Dengan adanya penelitian ini, penulis diharapkan dapat memberikan sumbangsih penelitian yang bermanfaat bagi masyarakat. Kemudian dapat diterapkan dan diteliti lagi lebih lanjut.
Dalam penelitian ini jumlah benda uji yang dibuat terdiri dari 240 buah silinder beton dengan ukuran $\varnothing 15 \mathrm{~cm}$ dan tinggi $30 \mathrm{~cm}$ dengan masingmasing variasi menggunakan 30 benda uji :

1. Pasir gunung merapi yang digunakan dalam penelitian ini adalah pasir yang berasal dari sisasisa material vulkanik yang dimuntahkan Gunung Merapi di Yogyakarta, sedangkan pasir Lumajang adalah pasir yang berasal dari campuran muntahan Gunung Semeru di Lumajang Jawa Timur.

2. Semen yang digunakan dalam penelitian ini adalah Semen Portland tipe I.

3. Komposisi masing-masing campuran menggunakan FAS (faktor air semen) antara 0.6, 0.5, 0.4 dan 0,3 .

4. Melakukan uji kuat tekan beton, pada umur 7, 14, dan 28 hari.

5. Melakukan perbandingan hasil uji kuat tekan beton pada umur 28 hari. 6. Melakukan uji statistik Anova.

Semua ini adalah untuk mengetahui kuat tekan beton dengan menggunakan pasir Lumajang dan pasir Gunug Merapi dan membandingkan kuat tekan beton antara pasir lumajang dengan pasir gunung merapi.

Diharapkan dalam penelitian ini, dapat memberikan masukan didalam penggunaan material pasir Lumajang dan pasir Gunung Merapi untuk campuran beton, sehingga dapat menjadi acuan sebagai material penyusun beton untuk konstruksi di Indonesia. Untuk Material penyusun beton agregat kasar, ditinjau dari berat jenisnya ada 3 macam yaitu : 
1. Agregat kasar ringan

Yaitu agregat yang memiliki berat jenis kurang dari 2,0 dan biasanya digunakan ntuk beton nonstructural.

2. Agregat kasar normal

Adalah agregat yang memiliki berat jenis antara 2,5 sampai 2,7. Beton menggunakan agregat normal biasanya memiliki berat jenis sekitar 2,3 dengan kuat desak antara $15 \mathrm{MPa}$ sampai $40 \mathrm{Mpa}$.

3. Agregat kasar berat

Agregat kasar jenis ini memiliki berat jenis lebih dari 2,8.

Sedangkan untuk agregat halus pada Pasir Lumajang merupakan pasir yang berasal dari campuran muntahan Gunung Semeru yang memiliki karakteristik butiran dan gradasi (susunan besar butiran) sangat bagus, dengan daya lekat (interlocking) juga bagus, sehingga dapat berpengaruh terhadap kekuatan (strength) dan ketahanan (durability) beton. Pada pasir gunung Merapi merupakan pasir dengan kualitas baik, karena partikel tersebut memiliki sudut. Pola partikel yang memiliki sudut itulah yang membuat ikatan pasir gunung merapi degan semen menjadi lebih kuat.

Untuk Semen Portland adalah bahan yang mempunyai sifat adhesive dan kohesif, yaitu bahan pengikat. Menurut Standart Industri Indonesia, SII 0013 - 1981, definisi semen portland adalah semen hidraulis yang dihasilkan dengan cara menghaluskan klinker yang terutama terdiri dari silikat silikat kalsium yang bersifat hidraulis.

Semen portland diklasifikasikan menjadi 5 jenis atau tipe menurut standart SII-0013-1981, terdiri atas :

1. Tipe I

Semen portland yang pada umumnya digunakan untuk pekerjaan teknik sipil dan tidak memerlukan persyaratan khusus.

2. Tipe II

Semen portland yang mempunyai kegunaan ketahanan terhadap sulfat dan kalor hidrasi sedang (lebih kecil dari tipe I).

3. Tipe III

Semen portland yang penggunaannya mempunyai kekuatan awal yang tinggi setelah pengikatan terjadi.

4. Tipe IV

Semen portland yang yang dalam penggunaannya memerlukan kalor hidrasi yang rendah, hamper sama dengan tipe II.

5. Tipe V

Semen porland yang dalam penggunaan memerlukan ketahanan tinggi terhadap sulfat.

Pemakaian air pada pembuatan beton mempunyai tujuan utama yaitu agar terjadi hidrasi, yaitu reaksi kimia antara semen dan air yang menyebabkan campuran ini menjadi keras setelah beberapa waktu tertentu. Air yang dibutuhkan agar menjadi proses hidrasi kira-kira 20\% dari berat semen. Pembebanan air ini harus dibatasi sebab dapat mengakibatkan berkurangnya kekuatan. Proses hidrasi akan berlangsung baik apabila dipakai air tawar, oleh karena itu air yang di gunakan untuk campuran beton harus memenuhi syarat berdasarkan SNI-032847-2002 yaitu :

1. Air yang digunakan pada campuran beton harus bersih dan bebas dari bahan-bahan yang merusak yang mengandung oli, asam, alkali, garam, bahan organik atau bahanbahan lainnya yang merugikan terhadap beton atau tulangan. 
2. Air pencampur yang digunakan pada beton prategang atau pada beton yang didalamnya tertanam logam aluminium, termasuk air bebas yang terkandung dalam agregat, tidak boleh mengandung ion klorida dalam jumlah yang membahayakan.

3. Air yang tidak dapat diminum tidak dapat digunakan pada beton kecuali ketentuan berikut terpenuhi :

a. Pemilihan proporsi campuran beton harus didasarkan pada campuran beton yang menggunakan air dari sumber air yang sama.

b. Hasil pengujian pada umur 7 dan 28 hari pada benda uji yang dibuat dengan adukan dengan air yang tidak dapat diminum harus mempunyai kekuatan sekurang-kurangnya sama dengan $90 \%$ dari kekuatan benda uji yang dibuat dengan air yang dapat diminum.

Sedangkan bahan tambahan atau Admixture adalah bahan-bahan yang ditambahkan ke dalam campuran beton pada saat atau selama pencampuran berlangsung. Fungsi dari bahan ini adalah untuk mengubah sifat-sifat dari beton agar menjadi lebih cocok untuk pekerjaan tertentu, atau untuk menghemat biaya.

Admixture atau bahan tambah didefinisikan dalam Standard Definitions Of Terminology Relating to Concrete and Concrete Aggregates (ASTM C.125-1995:61) dan dalam Cement and Concrete Terminology (ACI SP-19) sebagai material selain air, agregat dan semen hidrolik yang dicampurkan dalam beton sebelum atau selama proses pengadukan berlangsung.

Pada pengerjaan beton, pencampuran bahan-bahan penyusun beton dilakukan agar diperoleh suatu komposisi yang solid dari bahanbahan penyusun berdasarkan rancangan campuran beton. Komposisi campuran beton yang baik akan menghasilkan kuat tekan yang tinggi, akan tetapi jika pelaksanaannya tidak dikontrol dengan baik, kemungkinan dihasilkannya beton yang tidak sesuai dengan rencana akan semakin besar.

Secara umum prosedur pelaksanaan dalam pengerjaan beton adalah :

$\ddot{y}$ Persiapan

$\ddot{y}$ Penakaran (Batching).

ÿ Pencampuran dan pengadukan (Mixing).

$\ddot{y}$ Pengangkutan dan pengecoran.

$\ddot{y}$ Pemadatan (Compacting).

ÿ Penyelesaian (Finishing).

ÿ Perawatan (Curing).

Secara umum, diketahui bahwa semakin besar nilai FAS, semakin rendah mutu kekuatan beton. Dengan demikian, untuk menghasilkan sebuah beton yang bermutu tinggi FAS dalam beton haruslah rendah, sayangnya hal ini menyebabkan kesulitan dalam pengerjaannya. Umumnya nilai FAS minimum untuk beton normal sekitar 0,4 dan nilai maksimumnya 0,65 . (Mulyono, 2004).

Hubungan antara FAS dengan kuat tekan beton dinyatakan dalam pernyataan $\mathrm{f}^{\prime} \mathrm{c}=\mathrm{A} /\left(\mathrm{B}^{1.5 \mathrm{X}}\right)$, dimana $\mathrm{A}$ dan $\mathrm{B}$ adalah nilai konstanta, dan $\mathrm{X}$ adalah nilai FAS. Pada praktiknya, untuk mengatasi kesulitan pengerjaan karena rendahnya nilai FAS ini, ditambahkan bahan tambah yang bersifat menambah keenceran. 
Pada prinsipnya, perlu dilakukan perawatan yaitu untuk mencegah pengeringan yang bisa menyebabkan kehilangan air yang dibutuhkan untuk proses pengerasan beton atau mengurangi kebutuhan air selama proses hidrasi semen. Pencegahan ini terutama pada awal hari (umur awal) sampai beton berumur 14 hari (minimum moist curing). Lamanya perawatan ini juga tergantung dari jenis semen yang dipakai, misalnya tipe I, II dan V paling sedikit di curing 21 hari lamanya. Untuk tipe semen $\mathrm{V}$ proses pengerasan lebih lambat dari semen tipe I dan II, maka curingnya dianjurkan minimum 28 hari. Perawatan yang biasa dilakukan pada beton untuk mempertahankan kelembaban adalah:

- Menggenangi permukaan tanah atau pasir.

- Menutupi permukaan beton dengan air goni yang dibasahi air.

- Menutupi dengan tanah atau pasir.

- Menyirami beton secara kontinyu.

- Merendam beton dalam air.

Untuk perhitungan beton pada umur 28 hari, menggunakan perhitungan sebagai berikut :

$\ddot{y}$ Kuat Tekan Individu :

$$
f c^{\prime}=\frac{P}{A}
$$

ÿ Kuat Tekan Rata-rata :

$$
f c r=\sum_{i=1}^{n} f c i \div n
$$

ÿ Standar Deviasi :

$$
s=\sqrt{\frac{\sum_{i=1}^{n}(f c i-f c r)^{2}}{n-1}}
$$

$\ddot{y}$ Kuat Tekan Karakteristik :

$$
f c^{\prime}=f c r-(1,64 \times s)
$$

Dimana :

$\mathrm{P}=$ Beban maksimum $(\mathrm{kg})$.

$\mathrm{A}=$ Luas penampang benda uji $\left(\mathrm{cm}^{2}\right)$.

$\mathrm{s} \quad=$ Deviasi standar. $\left(\mathrm{kg} / \mathrm{cm}^{2}\right)$

$\mathrm{f}_{\mathrm{ci}}=$ Kuat tekan beton yang didapat dari hasil pengujian $\left(\mathrm{kg} / \mathrm{cm}^{2}\right)$.

$\mathrm{f}_{\mathrm{cr}}=$ Kuat tekan beton rata-rata $\left(\mathrm{kg} / \mathrm{cm}^{2}\right)$.

$\mathrm{n}=$ Jumlah benda uji, minimum 20 buah.

$\mathrm{fc}^{\prime}$ = Kuat tekan beton karakteristik $\left(\mathrm{kg} / \mathrm{cm}^{2}\right)$.

2. Metodologi

Perlu dilakukan persiapan material yang akan dipakai untuk pembuatan benda uji, yaitu :

- Semen Portland Type 1

- Air

- Agregat Kasar (Batu pecah)

- Agregat Halus (Pasir Lumajang dan Pasir Gunung Merapi)

- Bahan Tambah (Fly Ash dan Zat Additive)

Benda uji yang harus dibuat adalah silinder $\varnothing 15 \mathrm{~cm}$ dan tinggi $30 \mathrm{~cm}$ dimana proses pengecoran dilakukan dengan cara manual dengan dengan menggunakan FAS (faktor air semen) $0.6,0.5,0,4$ dan 0.3. Pembuatan benda uji ini adalah sesuai SNI-03-28472002.

Parameter yang digunakan dalam penelitian ini meliputi :

a. Penelitian dan pengujian bahan secara fisik

b. Pengujian kuat tekan beton pada umur 7, 14 dan 28 hari.

c. Evaluasi mutu beton (sesuai ASTM C-805-94)

J urnal APLIKASI: Media Informasi \& Komunikasi Aplikasi Teknik Sipil Terkini Halaman 17 
Tempat penelitian dilaksanankan adalah Laboratorium jaminan mutu dan inovasi PT. Varia Usaha Beton, J1 Letjen S Parman 38, SURABAYA.

3. Hasil Dan Pembahasan

Kondisi Pasir lumajang

- Asal : Lumajang

- Syarat Kebersihan

a. Kadar Organis :

(Bening)

Lebih muda

b. Kadar Lumpur: $1.4 \%$

- Modulus Kehalusan: -

- Berat Volume:
a. Lepas
$: 1,66 \mathrm{~kg} / \mathrm{m}^{3}$
b. Rojok
$: 1,67 \mathrm{~kg} / \mathrm{m}^{3}$
c. Goyang
$: 1,68 \mathrm{~kg} / \mathrm{m}^{3}$

- Kelembaban : -

- Berat Jenis : :2,60

- Kekerasan : -

- Resapan :2,8\%

- Grading Zone : 3

Kondisi Pasir Gunung Merapi

- Asal :Sleman

Yogjakarta

- Syarat Kebersihan

a. Kadar Organis :

(Kuning Muda) Lebih Muda

b. Kadar Lumpur: 5.4\%

- Modulus Kehalusan: -

- Berat Volume
a. Lepas
$: 1,61 \mathrm{~kg} / \mathrm{m}^{3}$
b. Rojok
: $1,73 \mathrm{~kg} / \mathrm{m}^{3}$
c. Goyang
$: 1,76 \mathrm{~kg} / \mathrm{m}^{3}$

- Kelembaban : -

- Berat Jenis : :2,58

- Kekerasan :

- Resapan : $4.38 \%$

- Grading Zone : 3
Analisa Material Agregat Kasar

Kondisi Batu Pecah 5/10

- Asal : Pandaan

- Syarat Kebersihan

a. Kadar Organis :

b. Kadar Lumpur: 3,8 \%

- Modulus Kehalusan: -

- Berat Volume
a. Lepas
$: 1,227 \mathrm{~kg} / \mathrm{m}^{3}$
b. Rojok
: $1,372 \mathrm{~kg} / \mathrm{m}^{3}$
c. Goyang
: $1,395 \mathrm{~kg} \mathrm{~m}^{3}$

- Kelembaban : -

- Berat Jenis : : 2,48

- Kekerasan : -

- Resapan :3,95\%

Kondisi Batu Pecah 10/20

- Asal : Pandaan

- Syarat Kebersihan

a. Kadar Organis : -

b. Kadar Lumpur: 4,6 \%

- Modulus Kehalusan: -

- Berat Volume
a. Lepas
: $1,192 \mathrm{~kg} / \mathrm{m}^{3}$
b. Rojok
$: 1,383 \mathrm{~kg} / \mathrm{m}^{3}$
c. Goyang
$: 1,387 \mathrm{~kg} \mathrm{~m}^{3}$

- Kelembaban : -

- Berat Jenis : :2,24

- Kekerasan : -

- Resapan : :4,82\%

Kondisi Batu Pecah 20/30

- Asal : Pandaan

- Syarat Kebersihan

a. Kadar Organis :

b. Kadar Lumpur: 2,85\%

- Modulus Kehalusan: -

- Berat Volume

$\begin{array}{ll}\text { Lepas } & : 1,267 \mathrm{~kg} / \mathrm{m}^{3} \\ \text { Rojok } & : 1,467 \mathrm{~kg} / \mathrm{m}^{3} \\ \text { Goyang } & : 1,475 \mathrm{~kg} \mathrm{~m} \mathrm{~m}^{3}\end{array}$


Kelembaban : -

Berat Jenis : 2,28

Kekerasan : :

Resapan : $2,93 \%$

Berdasarkan Gambar 1 terlihat bahwa :

Kuat tekan beton rata-rata pasir lumajang FAS 0,6 pada umur 7 hari adalah sebesar $204,115 \mathrm{~kg} / \mathrm{cm}^{2}$, pada umur 14 hari kuat tekan betonnya naik menjadi $218,386 \mathrm{~kg} / \mathrm{cm}^{2}$, dan pada umur 28 hari kuat tekan betonnya mengalami kenaikan sebesar 273,964 $\mathrm{kg} / \mathrm{cm}^{2}$.

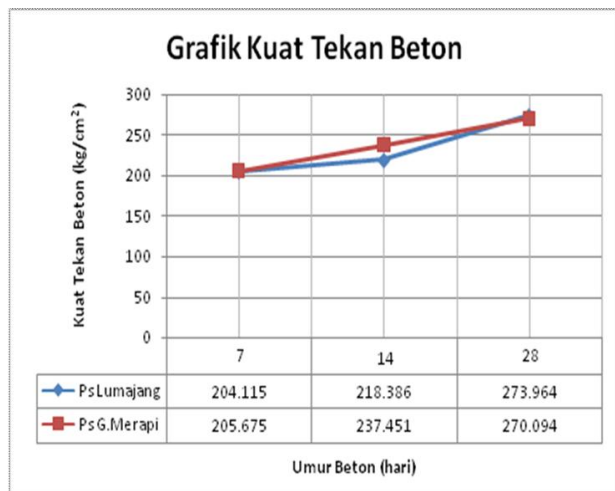

Gambar 1. Perbandingan Kuat tekan Beton antara pasir lumajang dengan pasir gunung merapi FAS 0,6.

Kuat tekan beton rata-rata pasir Gunung Merapi FAS 0,6 pada umur 7 hari adalah sebesar $205,675 \mathrm{~kg} / \mathrm{cm}^{2}$, pada umur 14 hari kuat tekan betonnya naik menjadi $237,451 \mathrm{~kg} / \mathrm{cm}^{2}$, dan pada umur 28 hari kuat tekan betonnya mengalami kenaikan sebesar 270,094 $\mathrm{kg} / \mathrm{cm}^{2}$.

Maka, kuat tekan beton pasir Lumajang FAS 0,6 memiliki kuat tekan optimum beton sebesar 273,964 $\mathrm{kg} / \mathrm{cm}^{2}$, dan kuat tekan beton optimum pasir Gunung Merapi FAS 0,6 sebesar $270,094 \mathrm{~kg} / \mathrm{cm}^{2}$. Sehingga untuk FAS 0,6 kuat tekan beton optimum kedua material belum memenuhi

Berdasarkan Gambar 2 terlihat bahwa kuat tekan beton rata-rata pasir lumajang FAS 0,5 pada umur 7 hari adalah sebesar $307,418 \mathrm{~kg} / \mathrm{cm}^{2}$, pada umur 14 hari kuat tekan betonnya naik menjadi $350,400 \mathrm{~kg} / \mathrm{cm}^{2}$, dan pada umur 28 hari kuat tekan betonnya mengalami kenaikan sebesar 402,570 $\mathrm{kg} / \mathrm{cm}^{2}$.

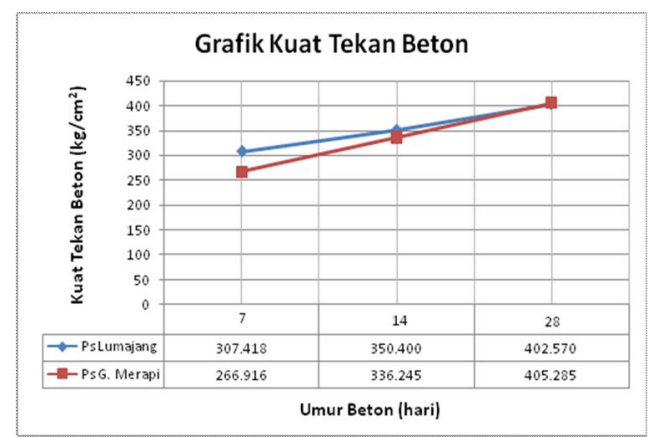

Gambar 2. Perbandingan Kuat tekan Beton antara pasir lumajang dengan pasir gunung merapi FAS 0,5.

Kuat tekan beton rata-rata pasir Gunung Merapi FAS 0,5 pada umur 7 hari adalah sebesar $266,916 \mathrm{~kg} / \mathrm{cm}^{2}$, pada umur 14 hari kuat tekan betonnya naik menjadi $336,245 \mathrm{~kg} / \mathrm{cm}^{2}$, dan pada umur 28 hari kuat tekan betonnya mengalami kenaikan sebesar 405,285 $\mathrm{kg} / \mathrm{cm}^{2}$.

Maka, kuat tekan beton pasir Lumajang FAS 0,5 memiliki kuat tekan optimum beton sebesar 402,570 $\mathrm{kg} / \mathrm{cm}^{2}$, dan kuat tekan beton optimum pasir Gunung Merapi FAS 0,5 sebesar $405,285 \mathrm{~kg} / \mathrm{cm}^{2}$. Sehingga untuk FAS 0,5 kuat tekan beton optimum kedua material telah memenuhi syarat kuat tekan (fc') yang direncanakan, yakni sebesar $300 \mathrm{~kg} / \mathrm{cm}^{2}$.

Berdasarkan Gambar 3 terlihat bahwa kuat tekan beton rata-rata pasir lumajang FAS 0,4 pada umur 7 hari adalah sebesar $324,401 \mathrm{~kg} / \mathrm{cm}^{2}$, pada umur 14 hari kuat tekan betonnya naik menjadi $380,731 \mathrm{~kg} / \mathrm{cm}^{2}$, dan pada umur 28 hari kuat tekan betonnya mengalami kenaikan sebesar 441,105 $\mathrm{kg} / \mathrm{cm}^{2}$. 


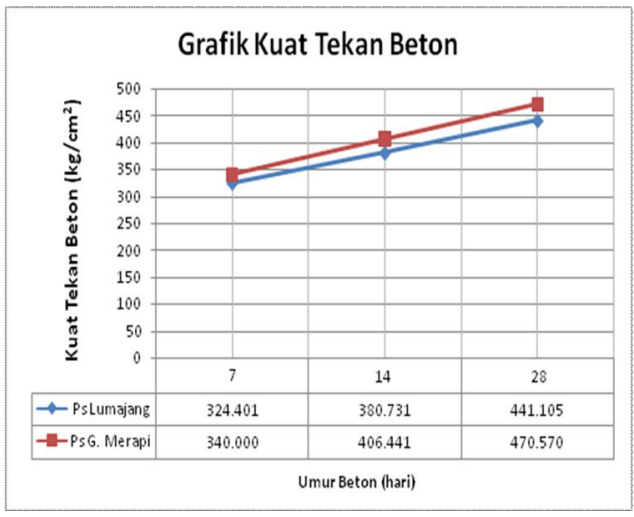

Gambar 3. Perbandingan Kuat tekan Beton antara pasir lumajang dengan pasir gunung merapi FAS 0,4.

Kuat tekan beton rata-rata pasir Gunung Merapi FAS 0,4 pada umur 7 hari adalah sebesar $340,000 \mathrm{~kg} / \mathrm{cm}^{2}$, pada umur 14 hari kuat tekan betonnya naik menjadi $406,441 \mathrm{~kg} / \mathrm{cm}^{2}$, dan pada umur 28 hari kuat tekan betonnya mengalami kenaikan sebesar 470,570 $\mathrm{kg} / \mathrm{cm}^{2}$.

Maka, kuat tekan beton pasir Lumajang FAS 0,4 memiliki kuat tekan optimum beton sebesar 441,105 $\mathrm{kg} / \mathrm{cm}^{2}$, dan kuat tekan beton optimum pasir Gunung Merapi FAS 0,4 sebesar $470,570 \mathrm{~kg} / \mathrm{cm}^{2}$. Sehingga untuk FAS 0,4 kuat tekan beton optimum kedua material telah memenuhi syarat kuat tekan (fc') yang direncanakan, yakni sebesar $300 \mathrm{~kg} / \mathrm{cm}^{2}$.

Berdasarkan Gambar 4 terlihat bahwa kuat tekan beton rata-rata pasir lumajang FAS 0,3 pada umur 7 hari adalah sebesar $414,529 \mathrm{~kg} / \mathrm{cm}^{2}$, pada umur 14 hari kuat tekan betonnya naik menjadi $512,456 \mathrm{~kg} / \mathrm{cm}^{2}$, dan pada umur 28 hari kuat tekan betonnya mengalami kenaikan sebesar 566,764 $\mathrm{kg} / \mathrm{cm}^{2}$.

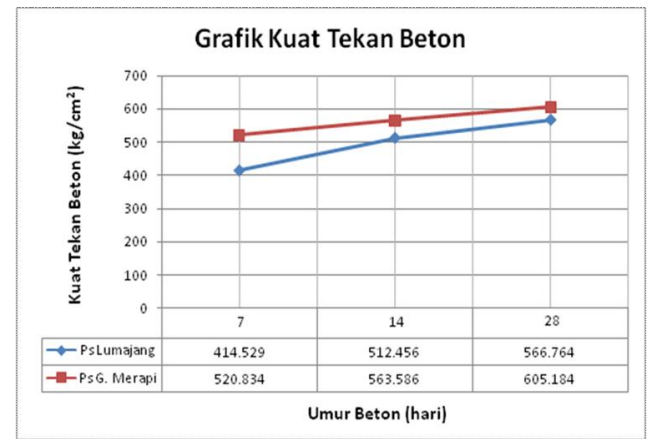

Gambar 4. Perbandingan Kuat tekan Beton antara pasir lumajang dengan pasir gunung merapi FAS 0,3.

Kuat tekan beton rata-rata pasir Gunung Merapi FAS 0,3 pada umur 7 hari adalah sebesar $520,834 \mathrm{~kg} / \mathrm{cm}^{2}$, pada umur 14 hari kuat tekan betonnya naik menjadi $563,586 \mathrm{~kg} / \mathrm{cm}^{2}$, dan pada umur 28 hari kuat tekan betonnya mengalami kenaikan sebesar 605,184 $\mathrm{kg} / \mathrm{cm}^{2}$.

Maka, kuat tekan beton pasir Lumajang FAS 0,3 memiliki kuat tekan optimum beton sebesar 566,764 $\mathrm{kg} / \mathrm{cm}^{2}$, dan kuat tekan beton optimum pasir Gunung Merapi FAS 0,3 sebesar $605,184 \mathrm{~kg} / \mathrm{cm}^{2}$. Sehingga untuk FAS 0,3 kuat tekan beton optimum kedua material telah memenuhi syarat kuat tekan (fc') yang direncanakan, yakni sebesar $300 \mathrm{~kg} / \mathrm{cm}^{2}$.

Berdasarkan Gambar 5 terlihat bahwa kuat tekan beton rata-rata hasil konversi pasir lumajang FAS 0,6 pada umur 28 hari adalah sebesar 270,241 $\mathrm{kg} / \mathrm{cm}^{2}$, Sedangkan kuat tekan beton rata-rata hasil konversi pasir gunung merapi FAS 0,6 pada umur 28 hari adalah sebesar $277,915 \mathrm{~kg} / \mathrm{cm}^{2}$. 


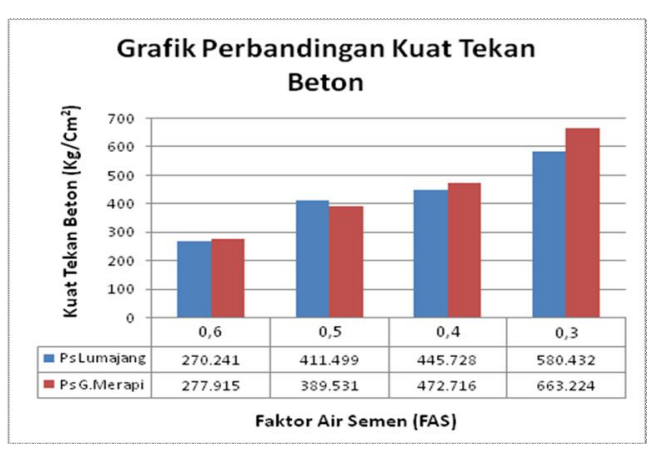

Gambar 5. Perbandingan konversi kuat tekan beton antara pasir lumajang dengan pasir gunung merapi pada umur 28 hari.

Sehingga untuk FAS 0,6, kuat tekan beton hasil konversi kedua material belum memenuhi syarat kuat tekan (fc') yang direncanakan, yakni sebesar $300 \mathrm{~kg} / \mathrm{cm}^{2}$.

Kuat tekan beton rata-rata hasil konversi pasir lumajang FAS 0,5 pada umur 28 hari adalah sebesar 411,499 $\mathrm{kg} / \mathrm{cm}^{2}$, Sedangkan kuat tekan beton rata-rata hasil konversi pasir gunung merapi FAS 0,5 pada umur 28 hari adalah sebesar $389,351 \mathrm{~kg} / \mathrm{cm}^{2}$. Sehingga untuk FAS 0,5, kuat tekan beton hasil konversi kedua material telah memenuhi syarat kuat tekan (fc') yang direncanakan, yakni sebesar 300 $\mathrm{kg} / \mathrm{cm}^{2}$.

Kuat tekan beton rata-rata hasil konversi pasir lumajang FAS 0,4 pada umur 28 hari adalah sebesar 445,728 $\mathrm{kg} / \mathrm{cm}^{2}$, Sedangkan kuat tekan beton rata-rata hasil konversi pasir gunung merapi FAS 0,4 pada umur 28 hari adalah sebesar $472,716 \mathrm{~kg} / \mathrm{cm}^{2}$. Sehingga untuk FAS 0,4, kuat tekan beton hasil konversi kedua material telah memenuhi syarat kuat tekan (fc') yang direncanakan, yakni sebesar 300 $\mathrm{kg} / \mathrm{cm}^{2}$.

Kuat tekan beton rata-rata hasil konversi pasir lumajang FAS 0,3 pada umur 28 hari adalah sebesar 580,432 $\mathrm{kg} / \mathrm{cm} 2$, Sedangkan kuat tekan beton rata-rata hasil konversi pasir gunung merapi FAS 0,3 pada umur 28 hari adalah sebesar $663,224 \mathrm{~kg} / \mathrm{cm}^{2}$. Sehingga untuk FAS 0,3 , kuat tekan beton hasil konversi kedua material telah memenuhi syarat kuat tekan (fc') yang direncanakan, yakni sebesar 300 $\mathrm{kg} / \mathrm{cm}^{2}$.

\section{Kesimpulan}

Berdasarkan hasil penelitian yang telah dilakukan dan analisa secara keseluruhan, mulai dari pengujian bahan material beton hingga pengujian tes kuat tekan beton, maka dapat ditarik kesimpulkan sebagai berikut :

1. Dari pengujian kuat tekan beton pada Faktor Air Semen (FAS) 0,6 umur 28 hari, didapatkan hasil kuat tekan beton pada material pasir Lumajang sebesar $270,241 \mathrm{~kg} / \mathrm{cm}^{2}$, sedangkan kuat tekan beton untuk pasir Gunung Merapi sebesar $277,915 \mathrm{~kg} / \mathrm{cm}^{2}$. Sehingga untuk pengujian Faktor Air Semen (FAS) 0,6 , kedua material belum memenuhi syarat kuat tekan beton rencana, yakni sebesar $300 \mathrm{~kg} / \mathrm{cm}^{2}$.

2. Dari pengujian kuat tekan beton pada Faktor Air Semen (FAS) 0,5 umur 28 hari, didapatkan hasil kuat tekan beton optimum pada material pasir Lumajang mengalami peningkatan sebesar $27 \%$ yakni sebesar $411,499 \mathrm{~kg} / \mathrm{cm}^{2}$, sedangkan kuat tekan beton optimum untuk pasir Gunung Merapi mengalami peningkatan sebesar 22,9\% yakni sebesar $389,351 \mathrm{~kg} / \mathrm{cm}^{2}$. Sehingga untuk pengujian Faktor Air Semen (FAS) 0,5, kedua material telah memenuhi syarat kuat tekan beton rencana, yakni sebesar $300 \mathrm{~kg} / \mathrm{cm}^{2}$.

3. Dari pengujian kuat tekan beton pada Faktor Air Semen (FAS) 0,4 umur 28 hari, didapatkan hasil kuat tekan beton optimum pada material pasir Lumajang mengalami 
peningkatan sebesar $32,6 \%$ yakni sebesar 445,728 kg/cm2, sedangkan kuat tekan beton optimum untuk pasir Gunung Merapi mengalami peningkatan sebesar $36,5 \%$ yakni sebesar $472,716 \mathrm{~kg} / \mathrm{cm}^{2}$. Sehingga untuk pengujian Faktor Air Semen (FAS) 0,4, kedua material telah memenuhi syarat kuat tekan beton rencana, yakni sebesar $300 \mathrm{~kg} / \mathrm{cm}^{2}$.

4. Dari pengujian kuat tekan beton pada Faktor Air Semen (FAS) 0,3 umur 28 hari, didapatkan hasil kuat tekan beton optimum pada material pasir Lumajang mengalami peningkatan sebesar $48,3 \%$ yakni sebesar $580,432 \mathrm{~kg} / \mathrm{cm}^{2}$, sedangkan kuat tekan beton optimum untuk pasir Gunung Merapi mengalami peningkatan sebesar $54,7 \%$ yakni sebesar 663,224 kg/ $\mathrm{cm}^{2}$. Sehingga untuk pengujian Faktor Air Semen (FAS) 0,3, kedua material telah memenuhi syarat kuat tekan beton rencana, yakni sebesar $300 \mathrm{~kg} / \mathrm{cm}^{2}$.

5. Dari hasil uji Statistik Anova satu arah, beton pasir Lumajang dan beton pasir Gunung Merapi pada Faktor Air Semen (FAS) 0,6 dinyatakan diterima, dikarenakan 'nilai F hitung < nilai F critical' yakni $=1,54<7,093$, jadi kuat tekan beton Pasir Lumajang sama dengan kuat tekan beton pasir Gunung Merapi. Sedangkan pada Faktor Air Semen (FAS) 0,5, 0,4, dan 0,3 dinyatakan ditolak, dikarenakan 'nilai $\mathrm{F}$ hitung > nilai F critical', dengan kata lain kuat tekan beton pasir Lumajang berbeda dengan kuat tekan beton pasir Gunung Merapi.
6. Pasir Gunung Merapi merupakan pasir dengan kualitas yang baik, sehingga dapat direkomendasikan sebagai bahan bangunan.

\section{Daftar Pustaka}

Arifin, Munif. 2009. Pasir Lumajang. http://lumajangtopic.blogspot.c om/2009/02/pasirlumajang.html.

L. J. Murdock, F. I. H. E. I, Stephanus Hindarko. 1986. Bahan dan Praktek Beton, edisi ke empat.

Mulyono, Tri. 2004. Teknologi Beton. Yogyakarta: Andi.

Peraturan Beton Bertulang Indonesia. 1971. Bandung: Departemen Pekerjaan Umum.

Departemen Perindutrian Republik Indoneia. 1980. Mutu dan Cara Uji Agregat Beton. Standar Industri Indonesia (SII) $0052-80$.

Departemen Perindustrian Republik Indoneia. 1980. Mutu dan Cara Uji Pasir Standard. Standar Industri Indonesia (SII) $0287-80$. 